\title{
Renal Function after Major Uro-Oncologic Surgery and Dexmedetomidine Infusion
}

\author{
Marcus Vinicius M. Novaes ${ }^{1}$, Paulo Sergio G. Lavinas ${ }^{1}$, Grace Haber D. Pires ${ }^{1}$, \\ Ana Claudia G. de Carvalho ${ }^{1}$, Renata M. B. Lopes ${ }^{1}$, Regina El Dib ${ }^{2}$, Paulo do Nascimento Jr. ${ }^{2}$ \\ ${ }^{1}$ Cancer Institute (INCA), Rio de Janeiro, Brazil; ${ }^{2}$ Department of Anesthesiology, Univ Estadual Paulista (UNESP), Botucatu, Brazil. \\ Email: paulonascimentojr@me.com
}

Received August $2^{\text {nd }}, 2013$; revised September $2^{\text {nd }}, 2013$; accepted September $19^{\text {th }}, 2013$

Copyright (C) 2013 Marcus Vinicius M. Novaes et al. This is an open access article distributed under the Creative Commons Attribution License, which permits unrestricted use, distribution, and reproduction in any medium, provided the original work is properly cited.

\begin{abstract}
Objective: Acute kidney injury in major surgery is associated with increased postoperative mortality. This study aimed to evaluate renal function after major urologic surgery and intraoperative dexmedetomidine infusion. Methods: Thirty oncologic patients with normal renal function scheduled for prostatectomy or nephrectomy, anesthetized with combined epidural and general anesthesia, were randomized to receive either intraoperative blind infusion of dexmedetomidine (Dexmedetomidine Group, $\mathrm{n}=15,0.5 \mu \mathrm{g} / \mathrm{kg}$ load dose plus $0.7 \mu \mathrm{g} / \mathrm{kg} / \mathrm{h}$ ) or $0.9 \%$ saline (Control Group, $\mathrm{n}=15$ ) until the end of surgery. Intraoperative and cumulative 24-hour diuresis, serum creatinine $\left(\mathrm{S}_{\mathrm{Cr}}\right)$, calculated creatinine clearance $\left(\mathrm{Cl}_{\mathrm{Cr}}\right)$ and serum cystatin $\mathrm{C}\left(\mathrm{S}_{\mathrm{Cys}}\right)$ at postoperative days 1,2 and 3 and 2 weeks after surgery were evaluated. Results: Mean \pm standard deviation values for intraoperative diuresis in Dexmedetomidine and Control Groups were 566 $\pm 396 \mathrm{~mL}$ and $298 \pm 153 \mathrm{~mL}$, respectively $(\mathrm{p}=0.014)$. Cumulative 24-hour diuresis in Dexmedetomidine and Control Groups was $1947 \pm 266 \mathrm{~mL}$ and $1748 \pm 237 \mathrm{~mL}$, respectively $(\mathrm{p}=0.91)$. Mean values of $\mathrm{S}_{\mathrm{Cr}}, \mathrm{Cl}_{\mathrm{Cr}}$ and $\mathrm{S}_{\mathrm{Cys}}$ were not significantly different from their baseline values in both groups and no significant differences were seen between groups at any moment for two weeks $(\mathrm{p}>0.05)$. Conclusion: According to the doses used in this study, despite an intraoperative increase in diuresis, intraoperative infusion of dexmedetomidine did not influence renal performance up to two weeks after major uro-oncologic surgery, as evaluated by $\mathrm{S}_{\mathrm{Cr}}, \mathrm{Cl}_{\mathrm{Cr}}$ and $\mathrm{S}_{\mathrm{Cys}}$.
\end{abstract}

Keywords: Dexmedetomidine; Renal Function; Nephrectomy; Prostatectomy; Epidural; General Anesthesia

\section{Introduction}

Acute kidney injury (AKI) is usually seen in the perioperative period, mainly after major surgeries [1]. It has been observed that postoperative elevated values of serum creatinine are associated with increases in time and cost of hospital stay and with high rates of morbidity and mortality [2]. Urological procedures are considered to be of high risk for the development of perioperative kidney injury [3], and nephrectomy has the highest potential to cause AKI [4].

Several strategies are used to either prevent or minimize perioperative AKI. These can be either pharmacological or nonpharmacological strategies, even involving early dialysis techniques [5]. Dexmedetomidine, an $\alpha_{2}$ agonist drug with sedative, analgesic, and diuretic properties [6], has been assessed in the protection of organs such as brain, heart, and kidneys and conflicting results have been obtained [7-9]. No drug, alone or in combination, was shown to be effective in preventing perioperative AKI until the present time [7].

In the present study, to test the hypothesis that dexmedetomidine enhances postoperative renal performance, its potential to increase diuresis and creatinine clearance was evaluated in major urologic surgery.

\section{Methods}

This prospective and randomized study was approved by the Institutional Review Board of the National Cancer Institute, Rio de Janeiro, Brazil. Thirty patients scheduled for nephrectomy or prostatectomy at the National Cancer Institute (Rio de Janeiro, Brazil), signed the Informed Consent and were included in the study. The following criteria were filled for the patients to be included in the study: American Society of Anesthesiologists 
(ASA) physical status 1 - 2 of both sexes; age, $30-65$ years; height, $1.50-1.90 \mathrm{~m}$; no history of renal dysfunction; serum creatinine $\leq 1.3 \mathrm{mg} / \mathrm{dL}$; and no contraindication to epidural block. Patients using diuretics and/or clonidine were excluded from the study.

All patients received diazepam, $10 \mathrm{mg}$, oral route, the night before surgery. In the operating room, patients were monitored (Datex Ohmeda Aespire, PSVPro inside, Madison, USA) with continuous electrocardiography, bispectral index, invasive blood pressure (by radial artery catheterization), pulse oximetry, and capnography, the latter after tracheal intubation. A large-bore peripheral intravenous (IV) line was inserted in the upper limb and a $500 \mathrm{~mL}$ bolus of lactated Ringer's solution was infused followed by a $8 \mathrm{~mL} / \mathrm{kg} / \mathrm{h}$ infusion throughout the surgery. Central venous access was also obtained after tracheal intubation.

Patients were then randomly divided into two groups for blind infusion of dexmedetomidine (Dexmedetomidine Group, $\mathrm{n}=15), 0.5 \mu \mathrm{g} / \mathrm{kg}$ in 20 minutes followed by an infusion of $0.7 \mu \mathrm{g} / \mathrm{kg} / \mathrm{h}$ until the end of surgery; or $0.9 \%$ saline (Control Group, $\mathrm{n}=15$ ), with the same infusion protocol until the end of surgery. An Anne infusion pump was used (Anne; Abbott, Abbott Park, USA) and the solutions were prepared by a person not involved in the anesthetic-surgical procedure. After initial bolus of solution in study, epidural anesthesia was induced with the patient in lateral decubitus, between the $\mathrm{L}_{2}$ and $\mathrm{L}_{3}$ segments and a fixed dose of $0.75 \%$ ropivacaine, $20 \mathrm{~mL}$, with morphine, $2 \mathrm{mg}$, was injected in all patients. General anesthesia was induced 20 minutes after epidural injection with target-controlled infusion (TCI) of propofol $(3.0-4.0 \mu \mathrm{g} / \mathrm{mL})$, neuromuscular blockade was achieved with cisatracurium $(0.2 \mathrm{mg} / \mathrm{kg})$ and tracheal intubation was preceded by administration of lidocaine, $1.5 \mathrm{mg} / \mathrm{kg}$ IV. Anesthesia was maintained with TCI propofol and cisatracurium as needed.

If a decrease greater than $30 \%$ of baseline occurred in the values for mean arterial pressure or a systolic blood pressure less than $80 \mathrm{mmHg}$ was present, administration of a $300 \mathrm{~mL}$ bolus of $6 \%$ hydroxyethyl starch solution (HES, mean molecular weight, $130 \mathrm{kDa}$; degree of substitution, 0.4 ) would be performed and could be repeated. Bradycardia was defined as a heart rate lower than 45 beats per minute and would be treated with atropine, 0.5 $\mathrm{mg}$ IV. Administration of packed red blood cells (pRBC) was established if the hematocrit value was below $25 \%$. If the values for the mean arterial pressure continued lower than the limits defined in the study even after volume replacement (HES and/or pRBC), administration of adrenaline, $2-4 \mu \mathrm{g} / \mathrm{min}$, would be performed and the administration of solution in study could be interrupted.

Other perioperative parameters included length of surgery, volume and type of liquids administered, and adrenaline use in the operating room and post anesthesia care unit (PACU).

Diuresis was evaluated on a cumulative basis in the intraoperative period and 4,12 , and 24 hours after surgery. At the first three postoperative days and two weeks after surgery, renal function was assessed by the values for serum creatinine $\left(\mathrm{S}_{\mathrm{Cr}}\right)$ and creatinine clearance $\left(\mathrm{Cl}_{\mathrm{Cr}}\right)$ by using the Cockroft-Gault equation [10]. Additionally, renal function was also assessed by the values for serum cystatin $\mathrm{C}\left(\mathrm{S}_{\mathrm{Cys}}\right)$ in the same moments.

Recording of hemodynamic variables was made at the following times: baseline (right after patient monitoring); 10 and 20 minutes after infusion of the study solution was initiated; 20 minutes after epidural blockade (before induction of general anesthesia); after tracheal intubation; immediately before surgical incision; after start of surgery; end of surgery; 1 and 2 hours after admission of the patient in PACU; and discharge from the PACU.

\section{Statistical Analysis}

The number of participants in this study was calculated from the difference observed in the clearance of postoperative creatinine after intraoperative administration of dexmedetomidine as compared to the group not receiving the drug, according to Frumento's study [11]. A minimum of 24 patients (divided into two randomized groups) was necessary for a statistical power of $80 \%$ with $\alpha=$ 0.05 . Continuous variables were presented as mean \pm standard deviation (SD) and compared with the Student's $t$ test. Variables with high variability were compared using the Mann-Whitney test. The chi-square test was used in proportions. Continuous variables were analyzed with ANOVA followed by the Bonferroni test when appropriate. For all analyses, $p<0.05$ was considered statistically significant and the SPSS software (v. 13.0) was used.

\section{Results}

Demographic characteristics and perioperative data are shown in Table 1. No significant difference was observed between groups, with the exception of the number of patients who received intraoperative adrenaline. Only one patient in the Control Group who underwent nephrectomy needed $\mathrm{pRBC}$ intraoperatively after a hematocrit value of $22 \%$ was detected.

In the intraoperative period, mean $\pm \mathrm{SD}$ values of urinary output in the Dexmedetomidine Group were significantly higher than in the Control Group: $566 \pm 396$ $\mathrm{mL}$ and $298 \pm 153 \mathrm{~mL}$, respectively $(\mathrm{p}=0.014)$. Cumulative urinary output in 4, 12 and 24 hours after surgery showed no difference between Dexmedetomidine Group and Control Group, as follows, respectively: $837 \pm 268$ $\mathrm{mL}$ and $674 \pm 197 \mathrm{~mL}(\mathrm{p}=0.30) ; 1230 \pm 229 \mathrm{~mL}$ and $1077 \pm 200 \mathrm{~mL}(\mathrm{p}=0.907) ; 1947 \pm 266 \mathrm{~mL}$ and $1748 \pm$ 
$237 \mathrm{~mL}(\mathrm{p}=0.91)$.

No significant changes were seen in postoperative mean values of serum creatinine and creatinine clearance for both, Dexmedetomidine Group and Control Group, according to their baseline values. No significant differences between groups were detected at any time point for these two variables (Table 2). Postoperative mean values of serum cystatin $\mathrm{C}$ did not show any significant difference between groups at any moment and remained at the normal range in both groups (Table 2).

The mean arterial pressure was significantly higher in Dexmedetomidine Group before and after surgical incision $(p<0.05)$. Heart rate was significantly lower in the Dexmedetomidine Group, both in the operating room and

Table 1. Characteristics and perioperative data of patients submitted to nephrectomy or prostatectomy receiving intraoperative dexmedetomidine (Dexmedetomidine Group) or $0.9 \%$ saline (Control Group).

\begin{tabular}{|c|c|c|c|}
\hline & Dexmedetomidine Group $(\mathrm{n}=15)$ & Control Group $(n=15)$ & $\mathrm{p}$ value \\
\hline Age (years) & $51 \pm 13$ & $56 \pm 10$ & 0.284 \\
\hline Weight $(\mathrm{kg})$ & $72 \pm 11$ & $68 \pm 9$ & 0.200 \\
\hline Height $(\mathrm{cm})$ & $167 \pm 7$ & $168 \pm 6$ & 0.574 \\
\hline Sex (Male/Female) & $11 / 4$ & $10 / 5$ & 0.690 \\
\hline ASA (I/II) & $5 / 10$ & $9 / 6$ & 0.143 \\
\hline Surgery (nephrectomy/prostatectomy) & $9 / 6$ & $6 / 9$ & 0.308 \\
\hline Length of surgery (minutes) & $227 \pm 101$ & $230 \pm 70$ & 0.852 \\
\hline Total volume of lactated Ringer's (mL) & $1900+920$ & $2053+924$ & 0.546 \\
\hline Total volume of HES (mL) & $900+660$ & $813+360$ & 0.858 \\
\hline Use of adrenaline in the operating room (n) & 5 & 11 & 0.028 \\
\hline Use of adrenaline in the PACU (n) & 2 & 0 & 0.143 \\
\hline
\end{tabular}

Age, weight, height and length of surgery, total volume of lactated Ringer's and hydroxyethyl starch (HES) are expressed as mean \pm SD. American Society of Anesthesiologists (ASA) physical status, type of surgery, use of adrenaline in the operating room and in post anesthesia care unit (PACU) are expressed as number of patients. No significant differences were seen between groups, excepted on the use of adrenaline in the operating room.

Table 2. Mean values and standard deviation for baseline and postoperative serum creatinine and calculated creatinine clearance, and postoperative serum cystatin $C$ of patients submitted to nephrectomy or prostatectomy receiving intraoperative dexmedetomidine or $\mathbf{0 . 9 \%}$ saline (Control). No significant differences were noted between groups.

\begin{tabular}{|c|c|c|c|c|c|c|}
\hline & \multirow{2}{*}{ Baseline } & 1 Day & 2 Days & 3 Days & 2 Weeks & \multirow{2}{*}{$\mathrm{p}$ value (ANOVA) } \\
\hline & & \multicolumn{4}{|c|}{ After surgery } & \\
\hline \multicolumn{7}{|c|}{ Serum creatinine (mg/dL) } \\
\hline Dexmedetomidine & $0.90 \pm 0.16$ & $1.09 \pm 0.25$ & $1.06 \pm 0.28$ & $1.00 \pm 0.28$ & $1.00 \pm 0.19$ & 0.260 \\
\hline Control & $0.89 \pm 0.18$ & $0.95 \pm 0.19$ & $0.94 \pm 0.25$ & $0.89 \pm 0.19$ & $0.88 \pm 0.16$ & 0.773 \\
\hline $\mathrm{p}$ value & 0.881 & 0.093 & 0.126 & 0.290 & 0.088 & \\
\hline \multicolumn{7}{|c|}{ Creatinine clearance (mL/min) } \\
\hline Dexmedetomidine & $97.9 \pm 24.5$ & $82.6 \pm 26.5$ & $86.4 \pm 30.7$ & $91.3 \pm 30.0$ & $88.1 \pm 23.1$ & 0.454 \\
\hline Control & $88.9 \pm 27.8$ & $81.9 \pm 22.6$ & $85.5 \pm 29.1$ & $87.7 \pm 23.4$ & $87.9 \pm 24.6$ & 0.916 \\
\hline $\mathrm{p}$ value & 0.358 & 0.785 & 0.731 & 0.919 & 0.947 & \\
\hline \multicolumn{7}{|l|}{ Serum cystatin $\mathrm{C}(\mathrm{mg} / \mathrm{L})$} \\
\hline Dexmedetomidine & & $0.80 \pm 0.37$ & $0.90 \pm 0.39$ & $0.82 \pm 0.33$ & $0.85 \pm 0.20$ & 0.846 \\
\hline Control & & $0.75 \pm 0.18$ & $0.84 \pm 0.19$ & $0.84 \pm 0.19$ & $0.85 \pm 0.14$ & 0.217 \\
\hline $\mathrm{p}$ value & & 0.631 & 0.127 & 0.461 & 0.966 & \\
\hline
\end{tabular}




\section{PACU $(\mathrm{p}<0.05)$ (Figure 1).}

\section{Discussion}

In this study, oncological patients were submitted to prostatectomy or nephrectomy and, besides an intraoperative increase in diuresis, no effects on postoperative renal function were observed with intraoperative infusion of dexmedetomidine.

Patients with urogenital cancer may develop renal dysfunction due to intrinsic renal disease or obstruction in the urinary tract. For these patients, the risk of aggravation in renal impairment is increased in the perioperative period [12]. It is well established that preoperative renal function, age, obesity, diabetes, hypertension and proteinuria, as well as the type of surgery, are prognostic factors for development of postoperative renal dysfunction [13]. The reduction in the glomerular filtration rate is an independent risk factor for cardiovascular events and mortality [14]. Therefore, strategies to preserve postoperative renal function have been searched. These strategies involve an adequate blood volume and perfu- sion of the renal tissue, avoidance of nephrotoxins exposure and some pharmacological methods with non-uniform efficacy [15].

Dexmedetomidine is an $\alpha_{2}$-agonist agent with an important sympatholytic activity [16] that reduces stress response to surgical procedures [17] and in intensive care units [18]. A possible beneficial effect on glomerular filtration rate was shown in both animal [19] and human studies [20]. Frumento et al. showed that dexmedetomidine improved renal performance after thoracotomy [11].

Incidence of AKI varies not only with the profile of the population studied, but also with the criteria used for evaluation, size and type of surgery. Sorbellini et al. studying patients after nephrectomy, found $14 \%$ of AKI [21]. A retrospective analysis of 225 patients who underwent nephrectomy showed a total of $43 \%$ incidence of AKI [13]. In the present study, according to the criteria used to assess renal function, two weeks after surgery renal function was similar to preoperative values in both groups and no influence of dexmedetomidine could be
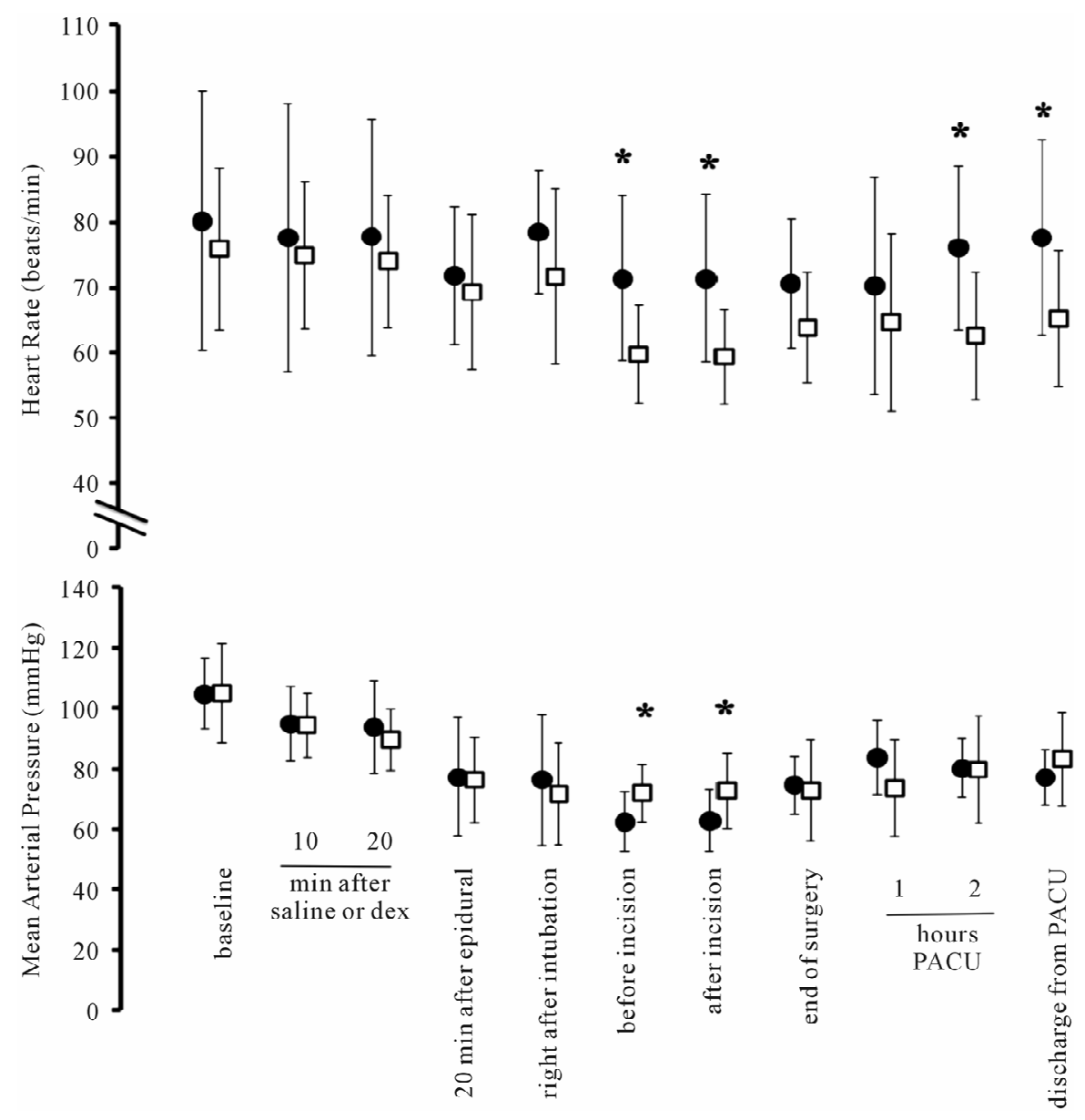

Figure 1. Mean values and SD for mean arterial pressure (bottom) and heart rate (top) at operating room and at post anesthesia care unit (PACU) of patients submitted to nephrectomy or prostatectomy receiving intraoperative dexmedetomidine ( $\square$ ) or $0.9 \%$ saline $(\bigcirc)$. ${ }^{*}$ p $<0.05$ vs. control group. 
determined. Probably, rigorous hemodynamic control and overall anesthetic management had a more important role in renal function than dexmedetomidine itself could have.

The significant increase in the intraoperative urine output with dexmedetomidine infusion confirms the findings of other authors [11,22]. The drug induces diuresis in animal models, possibly due to its sympatholytic property on the renal nerve [23]. It was also shown that dexmedetomidine decreases secretion and/or action of vasopressin, although it is unclear whether the diuretic effect is due in part to a better renal perfusion $[16,19]$. Dexmedetomidine increases secretion of the atrial natriuretic peptide which results in natriuresis [8] and inhibits renin secretion by the kidney [9]. Some studies have shown that not only diuresis but also perioperative renal function may be improved by $\alpha_{2}$-agonists [24]. However, others $[7,9]$ as well as the present study failed to show such benefit.

Cystatin $\mathrm{C}$ is an endogenous marker of renal function since it is freely filtered at the glomeruli and almost completely reabsorbed and catabolized in the proximal tubular cells [1]. In some studies, performance of this marker was considered superior to that of creatinine in the early diagnosis of renal dysfunction [25]. However, some other authors have not confirmed such superiority [26]. Kleber et al. [27] observed that the glomerular filtration rate estimated from serum creatinine was superior to that estimated by cystatin $\mathrm{C}$ in determining the initial stages of renal dysfunction. The study also points to a possible influence of some oncological diseases on cystatin $\mathrm{C}$ concentration. Although creatinine is specific, albeit not very sensitive, its levels do not significantly increase until the glomerular filtration rate falls to values lower than $50 \%$ of normal levels. Creatinine concentration is influenced by several factors, resulting in a large variation among individuals. Ahlstrom et al. prospectively analyzed 202 patients admitted to the intensive care unit, and concluded that creatinine was as efficient as cystatin C in detecting AKI [28].

Activation of $\alpha_{2}$ receptors promotes a significant reduction in circulating catecholamines, with moderate reduction in heart rate and blood pressure [16,22,29]. Regarding heart rate, our results followed those of these studies. In contrast, as reported by Dyck et al. [30], a significant increase in mean arterial pressure was observed in relation to the Control Group. This fact may be related to the different regimens of drug administration and associated techniques $[8,22,23]$.

The limitations of this study are that just one dose of dexmedetomidine was analyzed and different doses could have had a different response. Besides, evaluation of renal function was done by the mean of all subjects, a method similar to that seen in Frumento's study [11].
This may be criticized as small variations in serum creatinine values may result in the first stage of AKI [31]. Nonetheless, as we intended to study the overall profile, mean values of creatinine seem to be suitable. Creatinine is a common and cheap marker to analyze renal function. We understand that other more sensitive markers could also have a different behavior.

\section{Conclusion}

In conclusion, according to the doses used in this study, despite an intraoperative increase in diuresis, intraoperative infusion of dexmedetomidine did not influence renal performance up to two weeks after major uro-oncologic surgery as evaluated by serum creatinine, creatinine clearance and serum cystatin $\mathrm{C}$.

\section{Acknowledgements}

PNJ was supported by Fundação de Amparo à Pesquisa do Estado de São Paulo (FAPESP), grant \# 09/51984-5.

\section{REFERENCES}

[1] D. R. Jones and H. T. Lee, "Perioperative Renal Protection," Best Practice \& Research Clinical Anaesthesiology, Vol. 22, No. 1, 2008, pp. 193-208. http://dx.doi.org/10.1016/i.bpa.2007.08.005

[2] G. M. Chertow, E. Burdick, M. Honour, J. V. Bonventre and D. W. Bates, "Acute Kidney Injury, Mortality, Length of Stay, and Costs in Hospitalized Patients," Journal of the American Society of Nephrology, Vol. 16, No. 11, 2005, pp. 3365-3370.

http://dx.doi.org/10.1681/ASN.2004090740

[3] R. N. Sladen, "Anesthetic Considerations for the Patient with Renal Failure," Anesthesiology Clinics of North America, Vol. 18, No. 4, 2000, pp. 863-882. http://dx.doi.org/10.1016/S0889-8537(05)70199-1

[4] A. Cho, J. E. Lee, G. Y. Kwon, W. Huh, H. M. Lee, Y. G. Kim, D. J. Kim, H. Y. Oh and H. Y. Choi, "Post-Operative Acute Kidney Injury in Patients with Renal Cell Carcinoma Is a Potent Risk Factor for New-Onset Chronic Kidney Disease after Radical Nephrectomy," Nephrology Dialysis Transplantation, Vol. 26, No. 11, 2011, pp. 3496-3501. http://dx.doi.org/10.1093/ndt/gfr094

[5] R. Venkataraman and J. A. Kellum, "Prevention of Acute Renal Failure," Chest, Vol. 131, No. 1, 2007, pp. 300-308. http://dx.doi.org/10.1378/chest.06-1246

[6] J. E. Hall, T. D. Uhrich, J. A. Barney, S. R. Arain and T. J. Ebert, "Sedative, Amnestic, and Analgesic Properties of Small-Dose Dexmedetomidine Infusions," Anesthesia \& Analgesia, Vol. 90, No. 3, 2000, pp. 699-705. http://dx.doi.org/10.1097/00000539-200003000-00035

[7] K. Leino, M. Hynynen, J. Jalonen, M. Salmenpera, H. Scheinin and R. Aantaa, "Renal Effects of Dexmedetomidine during Coronary Artery Bypass Surgery: A Randomized Placebo-Controlled Study," BMC Anesthesiology, Vol. 11, 2011, p. 9. 
http://dx.doi.org/10.1186/1471-2253-11-9

[8] A. Bekker and M. K. Sturaitis, "Dexmedetomidine for Neurological Surgery," Neurosurgery, Vol. 57, No. 1, 2005, pp. 1-10.

http://dx.doi.org/10.1227/01.NEU.0000163476.42034.A1

[9] A. Bayram, A. Esmaoglu, A. Akin, G. Baskol, R. Aksu, C. Bicer, A. Demirtas, R. Mutluay and A. Boyaci, "The Effects of Intraoperative Infusion of Dexmedetomidine on Early Renal Function after Percutaneous Nephrolithotomy," Acta Anaesthesiologica Scandinavica, Vol. 55, No. 5, 2011, pp. 539-544.

http://dx.doi.org/10.1111/j.1399-6576.2011.02427.x

[10] D. W. Cockcroft and M. H. Gault, "Prediction of Creatinine Clearance from Serum Creatinine," Nephron, Vol. 16, No. 1, 1976, pp. 31-41. http://dx.doi.org/10.1159/000180580

[11] R. J. Frumento, H. G. Logginidou, S. Wahlander, G. Wagener, H. R. Playford and R. N. Sladen, "Dexmedetomidine Infusion Is Associated with Enhanced Renal Function after Thoracic Surgery," Journal of Clinical Anesthesia, Vol. 18, No. 6, 2006, pp. 422-426. http://dx.doi.org/10.1016/j.jclinane.2006.02.005

[12] P. Shenoy, P. Ward and T. Wigmore, "Surgical Management of Urological Malignancy: Anaesthetic and Critical Care Considerations," Current Anaesthesia \& Critical Care, Vol. 20, No. 1, 2009, pp. 22-27. http://dx.doi.org/10.1016/j.cacc.2008.10.005

[13] Y. Xu and B. Wu, "Prognostic Factors for Renal Dysfunction after Nephrectomy in Renal Cell Carcinomas," Journal of Surgical Research, Vol. 166, No. 1, 2011, pp. e53-e57. http://dx.doi.org/10.1016/j.jclinane.2006.02.005

[14] A. S. Go, G. M. Chertow, D. Fan, C. E. McCulloch and C. Y. Hsu, "Chronic Kidney Disease and the Risks of Death, Cardiovascular Events, and Hospitalization," The New England Journal of Medicine, Vol. 351, No. 13, 2004, pp. 1296-1305. http://dx.doi.org/10.1056/NEJMoa041031

[15] S. A. Josephs and C. V. Thakar, "Perioperative Risk Assessment, Prevention, and Treatment of Acute Kidney Injury," International Anesthesiology Clinics, Vol. 47, No. 4, 2009, pp. 89-105. http://dx.doi.org/10.1097/AIA.0b013e3181b47e98

[16] P. Talke, C. A. Richardson, M. Scheinin and D. M. Fisher, "Postoperative Pharmacokinetics and Sympatholytic Effects of Dexmedetomidine," Anesthesia \& Analgesia, Vol. 85, No. 5, 1997, pp. 1136-1142.

[17] F. G. Curtis, Y. M. Castiglia, A. A. Stolf, E. Ronzella, S. M. Vanni and P. Nascimento Junior, "Dexmedetomidine and Sufentanil as Intraoperative Analgesics: Comparative Study," Revista Brasileira de Anestesiologia, Vol. 52, No. 5, 2002, pp. 525-534.

[18] R. M. Venn, C. J. Bradshaw, R. Spencer, D. Brealey, E. Caudwell, C. Naughton, A. Vedio, M. Singer, R. Feneck, D. Treacher, S. M. Willatts and R. M. Grounds, "Preliminary UK Experience of Dexmedetomidine, a Novel Agent for Postoperative Sedation in the Intensive Care Unit," Anaesthesia, Vol. 54, No. 12, 1999, pp. 1136-1142. http://dx.doi.org/10.1046/j.1365-2044.1999.01114.x

[19] N. R. Villela, P. do Nascimento Junior, L. R. de Carvalho and A. Teixeira, "Effects of Dexmedetomidine on Renal System and on Vasopressin Plasma Levels. Experimental Study in Dogs," Revista Brasileira de Anestesiologia, Vol. 55, No. 4, 2005, pp. 429-440.

[20] D. L. Herr, S. T. Sum-Ping and M. England, "ICU Sedation after Coronary Artery Bypass Graft Surgery: Dexmedetomidine-Based versus Propofol-Based Sedation Regimens," Journal of Cardiothoracic and Vascular Anesthesia, Vol. 17, No. 5, 2003, pp. 576-584. http://dx.doi.org/10.1016/S1053-0770(03)00200-3

[21] M. Sorbellini, M. W. Kattan, M. E. Snyder, A. A. Hakimi, D. M. Sarasohn and P. Russo, "Prognostic Nomogram for Renal Insufficiency after Radical or Partial Nephrectomy," Journal of Urology, Vol. 176, No. 2, 2006, pp. 472476. http://dx.doi.org/10.1016/j.juro.2006.03.090

[22] A. M. De Wolf, R. J. Fragen, M. J. Avram, P. C. Fitzgerald and F. Rahimi-Danesh, "The Pharmacokinetics of Dexmedetomidine in Volunteers with Severe Renal Impairment," Anesthesia \& Analgesia, Vol. 93, No. 5, 2001, pp. 1205-1209. http://dx.doi.org/10.1097/00000539-200111000-00031

[23] H. Xu, M. Aibiki, K. Seki, S. Ogura and K. Ogli, "Effects of Dexmedetomidine, an Alpha2-Adrenoceptor agonist, on Renal Sympathetic Nerve Activity, Blood Pressure, Heart Rate and Central Venous Pressure in UrethaneAnesthetized Rabbits," Journal of the Autonomic Nervous System, Vol. 71, No. 1, 1998, pp. 48-54. http://dx.doi.org/10.1016/S0165-1838(98)00061-7

[24] P. J. Kulka, M. Tryba and M. Zenz, "Preoperative Alpha2-Adrenergic Receptor Agonists Prevent the Deterioration of Renal Function after Cardiac Surgery: Results of a Randomized, Controlled Trial," Critical Care Medicine, Vol. 24, No. 6, 1996, pp. 947-952. http://dx.doi.org/10.1097/00003246-199606000-00012

[25] V. R. Dharnidharka, C. Kwon and G. Stevens, "Serum Cystatin C Is Superior to Serum Creatinine as a Marker of Kidney Function: A Meta-Analysis," American Journal of Kidney Diseases, Vol. 40, No. 2, 2002, pp. 221-226. http://dx.doi.org/10.1053/ajkd.2002.34487

[26] S. Herget-Rosenthal, S. Trabold, J. Huesing, U. Heemann, T. Philipp and A. Kribben, "Cystatin C-An Accurate Marker of Glomerular Filtration Rate after Renal Transplantation?" Transplant International, Vol. 13, No. 4, 2000, pp. 285-289.

http://dx.doi.org/10.1111/j.1432-2277.2000.tb01083.x

[27] M. Kleber, M. Cybulla, K. Bauchmuller, G. Ihorst, B. Koch and M. Engelhardt, "Monitoring of Renal Function in Cancer Patients: An Ongoing Challenge for Clinical Practice," Annals of Oncology, Vol. 18, No. 5, 2007, pp. 950-958. http://dx.doi.org/10.1093/annonc/mdm055

[28] A. Ahlstrom, M. Tallgren, S. Peltonen and V. Pettila, "Evolution and Predictive Power of Serum Cystatin C in Acute Renal Failure," Clinical Nephrology, Vol. 62, No. 5, 2004, pp. 344-350.

[29] K. Dere, I. Sucullu, E. T. Budak, S. Yeyen, A. I. Filiz, S. Ozkan and G. Dagli, "A Comparison of Dexmedetomidine versus Midazolam for Sedation, Pain and Hemodynamic Control, during Colonoscopy under Conscious Sedation," European Journal of Anaesthesiology, Vol. 27, 
No. 7, 2010, pp. 648-652.

http://dx.doi.org/10.1097/EJA.0b013e3283347bfe

[30] J. B. Dyck, M. Maze, C. Haack, L. Vuorilehto and S. L. Shafer, "The Pharmacokinetics and Hemodynamic Effects of Intravenous and Intramuscular Dexmedetomidine Hydrochloride in Adult Human Volunteers," Anesthesiology, Vol. 78, No. 5, 1993, pp. 813-820. http://dx.doi.org/10.1097/00000542-199305000-00002

[31] R. L. Mehta, J. A. Kellum, S. V. Shah, B. A. Molitoris, C. Ronco, D. G. Warnock and A. Levin, "Acute Kidney Injury Network: Report of an Initiative to Improve Outcomes in Acute Kidney Injury," Critical Care, Vol. 11, No. 2, 2007, p. R31. http://dx.doi.org/10.1186/cc5713 